\title{
Review of "The kitchen as laboratory" edited by César Vega, Job Ubbink, and Erik van der Linden
}

\author{
Ole G Mouritsen *
}

\author{
Book details \\ Vega C, Ubbink J, van der Linden E \\ The Kitchen as Laboratory. Reflections on the Science of Food and Cooking. \\ New York: Columbia University Press; 2012 \\ 312 pages, ISBN 978-0-231-15344-7
}

Keywords: Science of food, Texture, Flavour, Composition, Cooking, Gastronomy

\section{Main text}

The book is a collection of 33 essays written by a wide range of scientists and chefs engaged in the intellectual and practical studies of food. The three editors, all versed themselves in the sciences inspired by cooking, have managed to put together an impressive mosaic of perspectives on the general theme of the kitchen viewed as a laboratory.

It is amazing how many exciting topics this small book with only 312 pages covers, all the way from the physics and physical chemistry of texture and preparatory techniques, over flavour and sensory perception, to the psychology and multi-sensory pleasure of eating.

Specific topics covered include: sensory experiences of the sound of crispness; crispy crusts and skins; sponge cakes; spherification and texture formation by hydrogels; sticky food and stretchable ice cream; conservation of meat and fish; flavour enhancement by Maillard reactions; gases and foams in cooking (e.g. for meringue and cappuccino); viscosity of egg yolk; the texture of ketchup; stocks, soups, sauces, and oil-water emulsions; heat transfer in cooking; the physics of sugar and sweets; restructuring of meats; and scientific observations in the restaurant and perceptions of the dining experience. Throughout the book, the various topics are dealt with in a way that revolves around the broad concept of flavour.

Correspondence: ogm@memphys.sdu.dk

MEMPHYS - Center for Biomembrane Physics, Department of Physics,

Chemistry, and Pharmacy, University of Southern Denmark, 55 Campusvej, Odense, M, DK-5230, Denmark
The interested layman can read the book, and at the same time it has refreshing and new insights to provide for both professional scientists and practitioners. The book can be used as a source of inspiration, it poses challenging questions (e.g. how to avoid the blooming of chocolate, how to optimize the life time of foams, or how to make a perfect crackling duck skin), it stimulates reflection and thoughtfulness (why we still don't know why egg whites whipped in a copper bowl make for a more stable foam), and at the same time it intrigues and encourages you to rush into your own kitchen and test the concrete ideas and detailed recipes (e.g. for chocolate chip cookies, tzatziki ice cream, crusty pizza, Nordic sushi (gravlax), grilled cheese sandwich, and salep dondurma). I can easily see how the book could also work as a valuable source for an elementary laboratory course on gastroscience.

Considering the diversity of topics and different personal styles of the contributors, the book is surprisingly well edited and homogeneous, while still maintaining the individuality of each contributor's approach to the topic. It is a lucid and very good read. There are a few misses, however. I am certainly repelled by the selfimportant contribution by $\mathrm{H}$. This who feels it is important to lecture to the reader who came first and what common terms like 'science', 'technology', and 'food' mean. Colour images would also most certainly have improved the value of the somewhat tedious-looking grey-tone book.

I received this new book in the mail just before going on a long weekend. I thought I would browse the book
C Biomed Central

(c) 2012 Mouritsen.; licensee BioMed Central Ltd. This is an Open Access article distributed under the terms of the Creative Commons Attribution License (http://creativecommons.org/licenses/by/2.0), which permits unrestricted use, distribution, and reproduction in any medium, provided the original work is properly cited. 
and maybe read a few selected chapters since I had already decided to spend the weekend reading an old book about smoked food. What I ended up doing was first randomly reading a few chapters of the new book, then a few more, and before returning back home after the weekend I found myself having read the entire book. Can I give any better recommendation?

\section{Competing interests}

The author declares that he has no competing interests.

Received: 10 April 2012 Accepted: 13 April 2012

Published: 8 August 2012

\section{Submit your next manuscript to BioMed Central} and take full advantage of:

- Convenient online submission

- Thorough peer review

- No space constraints or color figure charges

- Immediate publication on acceptance

- Inclusion in PubMed, CAS, Scopus and Google Scholar

- Research which is freely available for redistribution 